\title{
Temperature-decreasing and Humidity-increasing Effects of Typical Landscape Plants in Suzhou City
}

\section{Ying-ying LIU \& Yu-chen GUO \& Xiang-dong XIAO \& Sai WANG \& Xiao-ping LU \& Bo WANG ${ }^{b}$}

\author{
Department of horticulture, Soochow University, Suzhou, 215123, China \\ a1013916761@qq.com, bwangb@sud.edu.cn
}

KEYWORD: Landscape plants; Temperature-decreasing effect; Humidity-increasing effect

ABSTRACT: Garden trees play an integral role in supporting healthy urban communities as part of ecological system. 13 typical landscape plants, in Suzhou City, were selected to study the correlations among canopy width, vegetation quantity, branching point height and temperature-decreasing and humidity-increasing effects. This paper showed that different garden plants had various temperature-decreasing and humidity-increasing effects. Osmanthus fragrans (Thunb.) Lour., Zelkova schneideriana Hand.-Mazz., Cinnamomum porrectum (L.) Presl, Magnolia grandiflora L., Pinus massoniana Lamb., Ligustrum Lucidum Ait. and Diospyros Kaki Thunb. had more higher capacity, Platanus acerifolia Willd. and Pinus bungeana Zucc. were a little lower, and Bischofia polycarpa (Levl.) Airy-Shaw, Eriobotrya japonica (Thunb.) Lindl., Albizia julibrissin Durazz. and Liquidambar formosana Hance had the more lower effects on temperature-decreasing and humidity-increasing. Statistics showed that there was a significant positive correlation between the average canopy width and temperature-decreasing and humidity-increasing effects. Vegetation quantity and temperature-lowering had a significant positive correlation, in contrast, the vegetation quantity and humidity-increasing had not a significant positive correlation. Branching point height had effect to decrease temperature and humidity with a certain range.

\section{INTRODUCTION}

With dramatically increase of economical development, city size and population speed up the process of urbanization in Suzhou, the heat island effect, city haze, blue-green algae in Taihu lake and other, extreme weather events increased significantly; surface temperature in the urban area of Suzhou City center showed a beam-like distribution. Xiangcheng District, Wuzhong District and other places are the areas of high temperature vale (Yan et al., $2009 \&$ Yan et al., 2012). The heat island effect was found in the urban area of in 1980s; in the mid-1990s it expanded to Kunshan sip and Wujiang; in 2004, the heat island spread to the entire area of Suzhou city (Yan et al., 2010).

Landscape trees play an integral role, which represent a showcase of biodiversity, in supporting healthy urban communities through the provision of environmental, social and economic benefits. Plant is not only a representative to increase biodiversity but also an effective tool for urban Landscaping (Jennifer et al., 2015 \& Li et al., 2007 \& Stefano, 2014 ). During non heat extremes, for every $10 \%$ increase in the percentage of tree canopy explained a $0.2{ }^{\circ} \mathrm{C}$ decrease in air temperature variation (Paul et al., 2014). While, the most prominent feature of the garden plants is the ability to reduce the heat of solar radiation by changing the urban heat island effect (Man-zhu, 2009); meanwhile plants release moisture into the air through transpiration to increase air humidity.

In this paper, to provide a reference for the evaluation of the ecological garden city. 


\section{EXPERIMENTAL MATERIALS AND METHODS}

\section{Experimental Materials}

In this paper, 13 typical landscape plants, in Suzhou, Cinnamomum porrectum (L.) Presl, Magnolia grandiflora L., Zelkova schneideriana Hand.-Mazz., Albizia julibrissin Durazz., Bischofia polycarpa (Levl.) Airy-Shaw, Diospyros Kaki Thunb., Platanus acerifolia Willd., Osmanthus fragrans (Thunb.) Lour., Ligustrum Lucidum Ait., Pinus massoniana Lamb, Eriobotrya japonica (Thunb.) Lindl., Liquidambar formosana Hance and Pinus bungeana Zucc.were selected. Characterized in Table 1.

Table 1 . The characteristics of 13 typical landscape plants.

\begin{tabular}{ccccc}
\hline Species & $\begin{array}{c}\text { Canopy } \\
\text { width (m) }\end{array}$ & $\begin{array}{c}\text { Height of } \\
\text { the } \\
\text { branching } \\
\text { point }(\mathrm{m})\end{array}$ & $\begin{array}{c}\text { Leave area } \\
\text { index }\end{array}$ & $\begin{array}{c}\text { vegetation } \\
\text { quantity } \\
\left(\mathrm{m}^{2}\right)\end{array}$ \\
\hline 1 & 9.28 & 2.31 & 2.5658 & 173.46 \\
2 & 7.11 & 2.48 & 2.5215 & 100.06 \\
3 & 9.99 & 2.83 & 3.0595 & 239.69 \\
4 & 6.61 & 2.30 & 2.2688 & 77.82 \\
5 & 9.90 & 1.80 & 1.8382 & 141.43 \\
6 & 9.05 & 2.25 & 3.6056 & 231.82 \\
7 & 11.90 & 2.90 & 1.6136 & 179.37 \\
8 & 11.40 & 2.10 & 1.5930 & 162.52 \\
9 & 9.50 & 1.60 & 1.1714 & 82.99 \\
10 & 11.40 & 2.50 & 2.1601 & 220.37 \\
11 & 7.60 & 0.70 & 2.2585 & 102.41 \\
12 & 7.20 & 2.95 & 2.1172 & 86.16 \\
13 & 9.55 & 1.55 & 1.5975 & 114.37 \\
\hline
\end{tabular}

Note: Vegetation quantity equals the leave area index times the shadow space of the canopy area.

1 Cinnamomum porrectum (L.) Presl, 2 Magnolia grandiflora L., 3 Zelkova schneideriana Hand.-Mazz., 4 Albizia julibrissin Durazz., 5 Bischofia polycarpa (Levl.) Airy-Shaw, 6 Diospyros Kaki Thunb., 7 Platanus acerifolia Willd., 8 Osmanthus fragrans (Thunb.) Lour., 9 Ligustrum Lucidum Ait., 10 Pinus massoniana Lamb., 11 Eriobotrya japonica (Thunb.) Lindl., 12 Liquidambar formosana Hance, 13 Pinus bungeana Zucc.

\section{Experimental Methods}

The effects of temperature-decreasing and humidity-increasing in summer are most obvious, especially at 13:00-14:00 (Jun et al., 2009). Therefore, we processed at 13:00-14:00 on July 2014, with the breeze or calm winds. Temperature and humidity loggers (China, TES-1365) and wind speed measured equipment (China, FLUKE 923) are used to test the temperature and humidity of air and under the plants, which were $1.5 \mathrm{~m}$ high from the ground. Besides, laser rangefinder (China, Leica disto D5) was also used to measure the canopy width and branching points height of the garden plants. Used the tape to measure the tree's diameter, digital plant canopy image (China, SY-S01A) was used to analyzer trees leaf area index, leaf inclination and canopy density.

\section{Data Collecting and Processing}

WPS 2013, Microsoft Excel 2003 and IBM SPSS STATISTICS 19.0 were used to do the date analyses processing. The experimental data was used in the natural logarithm of the process. The measurement came from the reference researchers (Zhong et al., 2012), the calculation is as follows: 


$$
\begin{gathered}
c_{r}=\frac{r_{t}-u r_{t}}{r_{t}} \\
h_{r}=\frac{u r_{h}-r_{h}}{r_{h}}
\end{gathered}
$$

Where $c_{r} \stackrel{r h}{=}$ cooling rate; $r_{t}=$ reference temperature; $u r_{t}=$ under tree temperature; $h_{r}=$ humidification rate; $r_{h}=$ humidity reference; $u r_{h}=$ under tree humidity.

\section{RESULTS AND ANALYSIS}

\section{Temperature-decreasing Effect}

Figure 1 showed, different landscape plant had various temperature-decreasing function. The temperature drop range of Platanus acerifolia Willd. was the highest $\left(3.2{ }^{\circ} \mathrm{C}\right)$, the reducing rate of temperature upped to $8.38 \%$, which was about 8 times as much as that of Liquidambar formosana Hance. and Pinus massoniana Lamb.; the cooling rate of latter were lowest. The cooling rate of Zelkova schneideriana Hand.-Mazz. was $7.24 \%$, which was higher than others except Platanus acerifolia Willd.. The capacity order of their cooling were as follow: Platanus acerifolia Willd. > Zelkova schneideriana Hand.-Mazz. > Cinnamomum porrectum (L.) Presl > Magnolia grandiflora L. > Pinus massoniana Lamb. > Pinus bungeana Zucc.> Ligustrum Lucidum Ait. > Diospyros Kaki Thunb. > Osmanthus fragrans (Thunb.) Lour. > Bischofia polycarpa (Levl.) Airy-Shaw > Eriobotrya japonica (Thunb.) Lindl. > Liquidambar formosana Hance > Albizia julibrissin Durazz.

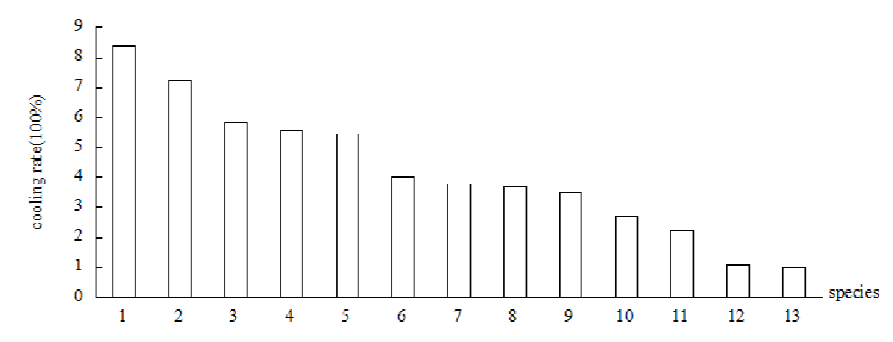

Figure 1. Cooing rate of various landscape plants. Taking the temperature of shadow was $0^{\circ} \mathrm{C}$ as $100 \%$.

Note: 1 Platanus acerifolia Willd., 2 Zelkova schneideriana Hand.-Mazz., 3 Cinnamomum porrectum (L.) Presl, 4 Magnolia grandiflora L., 5 Pinus massoniana Lamb., 6 Pinus bungeana Zucc., 7 Ligustrum Lucidum Ait., 8 Diospyros Kaki Thunb., 9 Osmanthus fragrans (Thunb.) Lour., 10 Bischofia polycarpa (Levl.) Airy-Shaw, 11 Eriobotrya japonica (Thunb.) Lindl., 12 Liquidambar formosana Hance, 13 Albizia julibrissin Durazz.

\section{The Correlation between Temperature-increasing Effect and Average Canopy Width, Vegetation quantity, Branching Point Height}

Different garden plants also have various temperature-decreasing effects because of their different internal factors. The average canopy width, vegetation quantity and branching point height and the cooling rate correlation were analyst, and the results were shown in Table 2.

(1) There was a significant positive correlation between temperature-decreasing effect and canopy width. From table 2, the correlation coefficient between temperature-decreasing effect and average canopy width was 0.684 that had a significant correlation $(p<0.01)$. With the canopy width increases, the reflection of solar radiation in and around the buildings are up to effectively block, greatly reducing the temperature of the surrounding plants, which play a role to drop the temperature. The larger the plant canopy width is, the temperature-decreasing effect is more obvious.

(2) There was a significant positive correlation between temperature-decreasing effect and vegetation quantity. From Table 2, the correlation coefficient and regression coefficient were 0.677 and 1.108 , and $p<0.01$, its correlation results significantly. With vegetation quantity increasing, the 
light energy utilization is raising and the overall transpiration is increasing, so as to achieve the temperature-decreasing effect. Meanwhile, with the increasing of vegetation quantity, the temperature-decreasing increases too.

(3) There was a positive correlation between temperature-decreasing and branching point height. From table 2, the correlation coefficient and regression coefficient were 0.217 and $0.126, p>0.05$. Therefore, the temperature-decreasing effect with branching point height had not significant correlated.

Table 2. The correlation between temperature-decreasing effect and average canopy width,

\begin{tabular}{cccc}
\multicolumn{3}{c}{ vegetation quantity, branching point height. } \\
\hline Term & $\mathrm{R}$ & $p$ & $\begin{array}{c}\text { Regression } \\
\text { coefficient }\end{array}$ \\
\hline $\begin{array}{c}\text { Canopy } \\
\text { width }\end{array}$ & 0.684 & 0.005 & $0.198^{* *}$ \\
$\begin{array}{c}\text { Vegetation } \\
\text { quantity }\end{array}$ & 0.677 & 0.005 & $1.108^{* *}$ \\
$\begin{array}{c}\text { Height of the } \\
\text { branching } \\
\text { point }\end{array}$ & 0.217 & 0.677 & 0.1257 \\
\hline
\end{tabular}

Note: *means significant difference in the 5\% level, $\quad * *$ means significant difference in the $1 \%$ level.

\section{Humidity-increasing effect}

Different landscape plants had various humidity-increasing effects. According to figure 2, the humidification rate of Ligustrum Lucidum Ait. reached $30.11 \%$, which was about 30 times as much as that of Liquidambar formosana Hance. Followed by Osmanthus fragrans (Thunb.) Lour., Zelkova schneideriana Hand.-Mazz. and Diospyros Kaki Thunb., the humidity-increasing effect upped to $16.18 \%, 14.64 \%$ and $10.22 \%$. That of Cinnamomum porrectum (L.) Presl, Magnolia grandiflora L. and Pinus massoniana Lamb. were little lower, the rate were close to $10.00 \%$. The lowest rate which was less than $3.00 \%$ was Liquidambar formosana Hance and Albizia julibrissin Durazz.. The capacity order of their humidification were Ligustrum Lucidum Ait. > Osmanthus fragrans (Thunb.) Lour. > Zelkova schneideriana Hand.-Mazz. > Diospyros Kaki Thunb. > Cinnamomum porrectum (L.) Presl > Magnolia grandiflora $L>$ Pinus massoniana Lamb. > Pinus bungeana Zucc. > Platanus acerifolia Willd. > Eriobotrya japonica (Thunb.) Lindl. > Bischofia polycarpa (Levl.) Airy-Shaw > Albizia julibrissin Durazz. > Liquidambar formosana Hance.

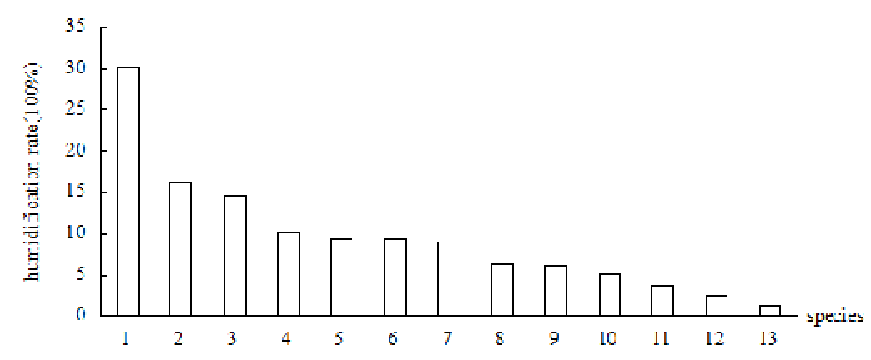

Figure 2. Humidification rate of various landscape plants. Taking the humidity of the shadow was two times of the air as $100 \%$.

Note: 1 Ligustrum Lucidum Ait., 2 Osmanthus fragrans (Thunb.) Lour., 3 Zelkova schneideriana Hand.-Mazz., 4 Diospyros Kaki Thunb., 5 Cinnamomum porrectum (L.) Presl, 6 Magnolia grandiflora L., 7 Pinus massoniana Lamb., 8 Pinus bungeana Zucc., 9 Platanus acerifolia Willd., 10 Eriobotrya japonica (Thunb.) Lindl., 11 Bischofia polycarpa (Levl.) Airy-Shaw, 12 Albizia julibrissin Durazz., 13 Liquidambar formosana Hance. 
The correlation between humidity-increasing effect and average canopy width, vegetation quantity, branching point height

Different species results vary humidity-increasing effect.

(1) There was a positive correlation between humidity-increasing effect and average canopy width (Table 3). The correlation coefficient was 0.52 and $p<0.05$. With canopy width increasing, humidity-increasing effect increasing, which was a positive correlation. It is possible to increase the frequency of use of larger canopy width species to create a good living environment combined with other factors.

(2) Vegetation quantity had effect to increase humidity with a certain range from Table 3 . The correlation coefficient and the regression coefficients were 0.384 and 0.798 and $p>0.05$, therefore the humidity-increasing effect and vegetation quantity showed a positive correlation, but the correlation between them was not obvious.

(3) The branching point height had effect to decrease humidity with a certain range (Table 3). The correlation coefficient and regression coefficient were -0.078 and -0.036 , humidity-increasing effect and branching point height was negative correlation. With the branching point height of the plant increasing, the permeability increasing, so it is much better for the air under the plant to circulate, That may explained the result.

(4) There was a significant positive correlation between humidity-increasing effect and temperature-lowering effect, which could be seen from Table 3. The correlation coefficient was 0.693 , and $p<0.01$. This indicated humidity-increasing effect and temperature-lowering effect had a significant relationship. With the rate of humidification increasing, the cooling rate increasing, or otherwise.

Table 3. The correlation between humidity-increasing effect and average canopy width, vegetation quantity, branching point height.

\begin{tabular}{cccc}
\hline Term & $\mathrm{R}$ & $p$ & $\begin{array}{c}\text { Regression } \\
\text { coefficient }\end{array}$ \\
\hline $\begin{array}{c}\text { Canopy width } \\
\text { Vegetation } \\
\text { quantity }\end{array}$ & 0.52 & 0.034 & $0.1187^{*}$ \\
$\begin{array}{c}\text { Height of the } \\
\text { branching } \\
\text { point }\end{array}$ & -0.078 & 0.399 & 0.798 \\
$\begin{array}{c}\text { Cooling rate } \\
\text { coling }\end{array}$ & 0.693 & 0.004 & $0.880^{* *}$ \\
\hline
\end{tabular}

Note: *means significant difference in the $5 \%$ level, **means significant difference in the $1 \%$ level.

\section{Conclusions}

Osmanthus fragrans (Thunb.) Lour., Zelkova schneideriana Hand.-Mazz., Cinnamomum porrectum (L.) Presl, Magnolia grandiflora L., Pinus massoniana Lamb., Ligustrum Lucidum Ait. and Diospyros Kaki Thunb. had higher capacity, Platanus acerifolia Willd. and Pinus bungeana Zucc.were a little lower, and Bischofia polycarpa (Levl.) Airy-Shaw, Eriobotrya japonica (Thunb.) Lindl., Albizia julibrissin Durazz. and Liquidambar formosana Hance had lower effects on temperature-decreasing and humidity-increasing.

While, there were correlation between humidity-increasing and temperature-lowering effects and vegetation quantity, canopy width and vegetation quantity. Different landscape plants had various temperature-decreasing and humidity-increasing functions. Differences in temperature-decreasing and humidity-increasing effects were greatly affected by plant species, canopy width, vegetation quantity and other factors. There was a significant positive correlation between the average canopy width and temperature-decreasing and humidity-increasing effects. Vegetation quantity and temperature-lowering had a significant positive correlation, in contrast, the vegetation quantity and humidity-increasing had not a significant positive correlation. Branching 
point height had effect to decrease temperature and humidity with a certain range. In addition, with the humidification rate increasing, the cooling rate increasing.

\section{References}

[1] Jennifer M. \& Terry L. \& Stephen J - T. 2015. A review of benefits and challenges in growing street trees in paved urban environments. Landscape and Urban Planing 134:157-166.

[2] Jun Qin \& Li-mian Wang \& Yong-hong $\mathrm{Hu} \&$ et al. 2009. Effect of plant community on temperature lowering and humidity increasing in residential areas of Shanghai. Journal of Ecology and Rural Environment 25(1):92-95, (in Chinese).

[3] Li Ni \& Shou-yun Shen \& Pei-sen Huang. 2007. Research on city gardening to reduce the urban heat island effect of Changsha city. Journal of Central South University of Forestry and Technology 27(2):36-43, (in Chinese).

[4] Man-zhu Bao. 2009. The role and mission of landscape architecture under the background of global climate change. Chinese Landscape Architecture 2:4-8, (in Chinese).

[5] Paul C \& Larissa L. 2014. How factors of land use / land cover, building configuration, and adjacent heat sources and sinks explain Urban Heat Islands in Chicago. Landscape and Urban Planning 125:117-129.

[6] Stefano B. 2014. Wildflower green roofs for urban landscaping, ecological sustainability and biodiversity. Landscape and Urban Planning. 124:151-161.

[7] Yan Zhu \&Lian-fang ZhuY \& Yong-ming Xu. 2010. Study on the urban heat island of Suzhou city based on landsat remote sensing data. Plateau Meteorology 29(1):244-250, (in Chinese).

[8] Yan Zhu \& Lian-fang Zhu. 2009. An analysis on summer urban heat island in Suzhou using satellite data. Journal of the Meteorological Sciences 29(1):77-83, (in Chinese).

[9] Yan Zhu \& Jin-biao Yang \& Lian-fang Zhu \& et al. 2012. The investigation of the relationship between urbanization process and climate change in Suzhou. Journal of the Meteorological Sciences 32(3):317-324, (in Chinese).

[10]Zhong Qin \& Cheng-bao Ba \& Zhan-dong Li. 2012. Effects of different plant communities on temperature reduction and humidity increase in Beijing. Ecological Science 31(5): 567-571, (in Chinese). 